\title{
Isolamento do gene ALS e investigação do mecanismo de resistência a herbicidas em Sagittaria montevidensis
}

\author{
Isolation of the ALS gene and investigation of the mechanism of herbicide resistance in \\ Sagittaria montevidensis
}

\author{
Aldo Merotto Junior ${ }^{\text {I }}$ Valmir Kupas ${ }^{\text {II }}$ Anderson Luis Nunes ${ }^{\text {III }}$ \\ Ives Clayton Gomes dos Reis Goulart ${ }^{\text {III }}$
}

- NOTA -

\section{RESUMO}

Diversos biótipos de sagitária (Sagittaria montevidensis Cham. \& Schlecht) foram constatados como resistentes a herbicidas inibidores da enzima ALS no Brasil e em outros locais do mundo. Os objetivos deste trabalho foram isolar e sequenciar o gene ALS de sagitária de forma a identificar a ocorrência de mutações relacionadas ao mecanismo de resistência de insensibilidade do local da ação de herbicidas. $O$ material vegetal consistiu de sementes de sagitária coletadas em lavouras de arroz irrigado localizadas na região Sul do Estado de Santa Catarina. Nove pares de sequências nucleotidicas iniciadoras foram desenhadas para a amplificação dos domínios $C, A$ e $D$ do gene ALS. As sequências nucleotídicas dos fragmentos amplificados com quatro pares de oligonucleotideos inciadores resultaram em amplicons com 360 a 393 nucleotídeos. Essas sequências apresentaram homologia com o gene ALS padrão de Arabdopsis thaliana e arroz, possuindo apenas três mutações de ponto. Uma dessas alterações foi a mutação Pro ${ }_{197}$ Phe, que é relacionada à ocorrência de resistência à herbicida em diversas espécies vegetais. As sequências obtidas evidenciaram que o gene ALS avaliado encontrava-se em heterozigose. Esses resultados sugerem a ocorrência de insensibilidade do local de ação como mecanismo de resistência a herbicidas inibidores de ALS em sagitária. A prevenção e o controle da resistência a herbicidas inibidores da ALS em sagitária devem ser fundamentados na rotação de herbicidas com diferentes mecanismos de ação.

Palavras-chave: $A H A S$, acetolactato sintase, pyrazosulfuronethyl, sagitária.

\section{ABSTRACT}

California arrowhead (Sagittaria montevidensis Cham. \& Schlecht) is an aquatic weed often found in rice paddy fields. Several biotypes of California arrowhead resistant to ALS-inhibiting herbicides were found in Brazil and in several rice fields worldwide. The objective of this study was to sequence the ALS gene of California arrowhead and to identify the occurrence of mutations related to target site insensitivity as the mechanism of herbicide resistance. The plant material consisted of seeds collected in rice paddy fields located in the state of Santa Catarina, Brazil. Nine pairs of primers were designed for the amplification of the domains $C, A$ and $D$ of the ALS gene. PCR reactions with four pairs of primers resulted in amplification of fragments with size close to expected, ranging from 360 to 393 nucleotides. These sequences showed high homology to the standard ALS gene Arabdopsis thaliana and rice having only three point mutations. One of these mutations was Pro ${ }_{197}$ Phe that is related with herbicide resistance in several weeds. The sequences obtained indicated that the ALS gene evaluated was heterozygous. These results suggest the occurrence of insensitivity of the site of action as the mechanism of resistance to ALS-inhibitors herbicides in California arrowhead. The prevention and control of resistance to ALSinhibitors in California arrowhead should be based on the rotation of herbicides with different mechanisms of action.

Key words: acetolactate synthase, AHAS, California arrowhead, giant arrowhead, pyrazosulfuronethyl.

IPrograma de Pós-graduação em Fitotecnia, Departamento de Plantas de Lavoura, Faculdade de Agronomia, Universidade Federal do Rio Grande do Sul (UFRGS). Av. Bento Gonçalves, 7712, 91501-970, Porto Alegre, RS, Brasil. E-mail: merotto@ufrgs.br. Autor para correspondência.

"Faculdade de Agronomia, UFRGS, Porto Alegre, RS, Brasil.

II'Programa de Pós-graduação em Fitotecnia, UFRGS, Porto Alegre, RS, Brasil. 
Sagittaria montevidensis Cham. \& Schlecht., conhecida como sagitária, aguapé de flexa ou flexa, é uma planta daninha aquática encontrada frequentemente em lavouras de arroz irrigado cultivadas no sistema pré-germinado ou de transplante. Sagitária é considerada como uma planta com baixa capacidade de competição com o arroz em comparação com outras plantas daninhas dessa cultura (GIBSON et al., 2001). No entanto, a elevada frequência de altas infestações de sagitária tem resultado em intensificação da utilização de herbicidas para o seu controle. Diversos biótipos de sagitária foram constatados como resistentes a herbicidas inibidores da enzima ALS. Inicialmente, três e quatro anos após a utilização do herbicida bensulfuron, plantas de sagitária resistentes a esse herbicida foram identificadas nos anos de 1993 e 1994, na Califórnia, nos Estados Unidos, e em New South Wales, Austrália, respectivamente (PAPPASFADER et al., 1994; HEAP, 2010). No Brasil, populações resistentes ao herbicida pyrazosulfuron-ethyl foram identificadas em 1999, em áreas tratadas com esse herbicida por cinco safras consecutivas (NOLDIN et al., 1999). Biótipos resistentes de sagitária também foram identificados na China, em 2003 (HEAP, 2010). Atualmente, a infestação de sagitária resistente a herbicidas inibidores da ALS está distribuída em várias áreas de cultivo de arroz pré-germinado no Estado de Santa Catarina e em algumas áreas no Rio Grande do Sul.

O herbicida pyrasulfuron-ethyl aplicado em um biótipo de sagitária resistente a esse herbicida apresentou menor efeito quando a aplicação foi realizada nas raízes em comparação com a aplicação na parte aérea, indicando uma possível restrição de absorção ou translocação do herbicida como mecanismo de resistência (CONCENÇO et al., 2007). Nesse trabalho, o biótipo resistente apresentou maior velocidade de germinação, vigor inicial, altura e produção de sementes em relação ao biótipo suscetível, indicando também que a diferente sensibilidade da forma de aplicação do herbicida pode estar relacionada ao conjunto de diferenças entre os biótipos analisados. O conhecimento do mecanismo de resistência de plantas daninhas a herbicidas é necessário para a determinação de práticas de manejo que objetivem a prevenção da ocorrência de novos biótipos resistentes e, principalmente, para a correta determinação das práticas de controle das plantas resistentes. O mecanismo de resistência a herbicidas inibidores de ALS mais frequente é a insensibilidade do local de ação (POWLES \& YU, 2010). Diversos procedimentos podem ser utilizados para o diagnóstico do mecanismo de resistência a herbicidas em plantas (CORBETT \&
TARDIFF, 2006). Entre essas técnicas, o isolamento e sequenciamento do gene alvo do herbicida podem identificar mutações conhecidas que causam insensibilidade ao herbicida. No entanto, essa estratégia requer o conhecimento prévio da sequência nucleotídica do gene de interesse da espécie em estudo para a obtenção dos oligonucleotídeos iniciadores que proporcionem a amplificação do gene. As ferramentas de sequenciamento de DNA de nova geração proporcionarão maiores facilidades para a identificação de mutações e alterações da composição nucleotídica de genes (CARVALHO \& SILVA, 2010). Entretanto, essas tecnologias ainda apresentam custo elevado e dificuldade de operacionalização em espécies com genoma desconhecido. Até o momento, a sequência nucleotídica do gene ALS de sagitária não é conhecida. Os objetivos deste trabalho foram isolar e sequenciar o gene ALS de sagitária de forma a identificar a ocorrência de mutações nesse gene relacionadas à ocorrência do mecanismo de resistência de insensibilidade do local da ação de herbicidas.

O material vegetal consistiu de sementes de sagitária coletadas de plantas individuais presentes em lavouras de arroz irrigado localizadas na região Sul do Estado de Santa Catarina, no mês de março de 2008. As lavouras onde a coleta foi realizada foram tratadas por no mínimo cinco anos com o herbicida pyrazosulfuron-ethyl e apresentavam limitação de controle a esse produto. As sementes foram semeadas em vasos contendo solo hidromórfico, em casa-devegetação. Quando as plantas possuíam três a quatro folhas, uma amostra de $100 \mathrm{mg}$ foi retirada para extração de DNA. As amostras de DNA foram quantificadas em gel de agarose a $2 \%$, sendo utilizados marcadores de tamanho de $100 \mathrm{pb}$. As sequências oligonucleotídicas iniciadoras utilizadas para o isolamento do gene ALS foram desenhadas com base nas sequências disponíveis no GenBank: AB049822, AB301496 e AB477097, por meio do programa Primo Pro 3.4. Três sequências nucleotídicas iniciadoras foram obtidas para o sentido senso (SagF1, SagF2 e SagF3) e três para o sentido reverso (SagR1, SagR2 e SagR3), com o objetivo de ampliar o gene ALS correspondente aos domínios C, Ae D descritos em MEROTTO et al. (2009). As reações de PCR foram realizadas de acordo com o protocolo descrito em MEROTTO et al. (2009). Os produtos da reação foram separados em gel de agarose (2\%) corado com brometo de etídio. O gel foi fotografado com o aparelho Kodak Digital Science 1D. Os amplicons correspondentes aos tamanhos esperados foram isolados do gel de agarose e purificados por meio do procedimento de precipitação com etanol. O sequenciamento de DNA foi realizado 
com o equipamento ABI 3100 Genetic Analyzer (Applied Biosystems do Brasil). O alinhamento da sequência obtida foi realizado com a sequência padrão do gene ALS de Arabidopsis thaliana (X51514) e com a proteína ALS de Oryza sativa (BAB20812). A sequência obtida foi deposita no Genbank sob o número HM212418.

As combinações dos três oligonucleotídeos iniciadores senso e três reverso resultaram em nove pares de sequências a serem avaliadas nas amostras de DNA das plantas de sagitária coletas em áreas com evidências da ocorrência de resistência ao herbicida pyrazosulfuron-ethyl. Com base no conhecimento da localização de pareamento de cada oligonucleotídeo iniciador no gene ALS, foi estabelecido o tamanho esperado do fragmento para cada par de ogonucleotídeos em avaliação. Os tamanhos esperados variaram de 362 a $488 \mathrm{pb}$ (dados não apresentados). Reações de PCR foram realizadas de forma a otimizar a amplificação de fragmentos de DNA. As reações de PCR com os pares de oligonucleotídeos SagF1/SagR2, SagF1/SagR3, SagF2/SagR2 e SagF3/SagR2 resultaram em amplificação de fragmentos com tamanho próximo ao esperado para esses oligonucleotídeos.

As sequências de DNA desses fragmentos indicaram a ocorrência de homologia com o gene ALS padrão da espécie Arabdopsis thaliana e de arroz. O fragmento amplificado com o oligonucleotídeo senso SagF2 (5'AAGGGCGCGGACATCCTCGT3') e reverso SagR2 (5'CTGGTGGCGAGATAGAAGG3') resultou em 393 nucleotídeos, correspondendo a 131 aminoácidos (Figura 1A). Essa sequência apresentou alta homologia

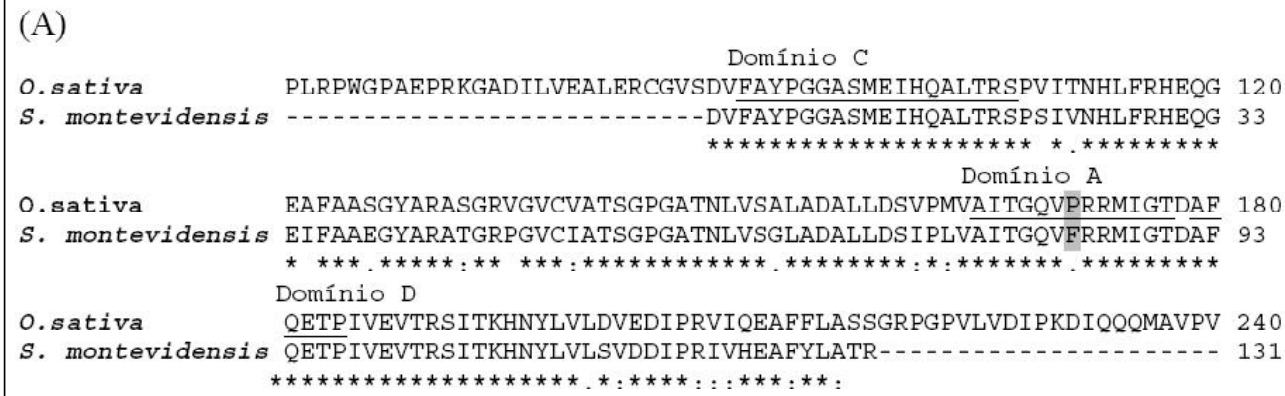

(B)

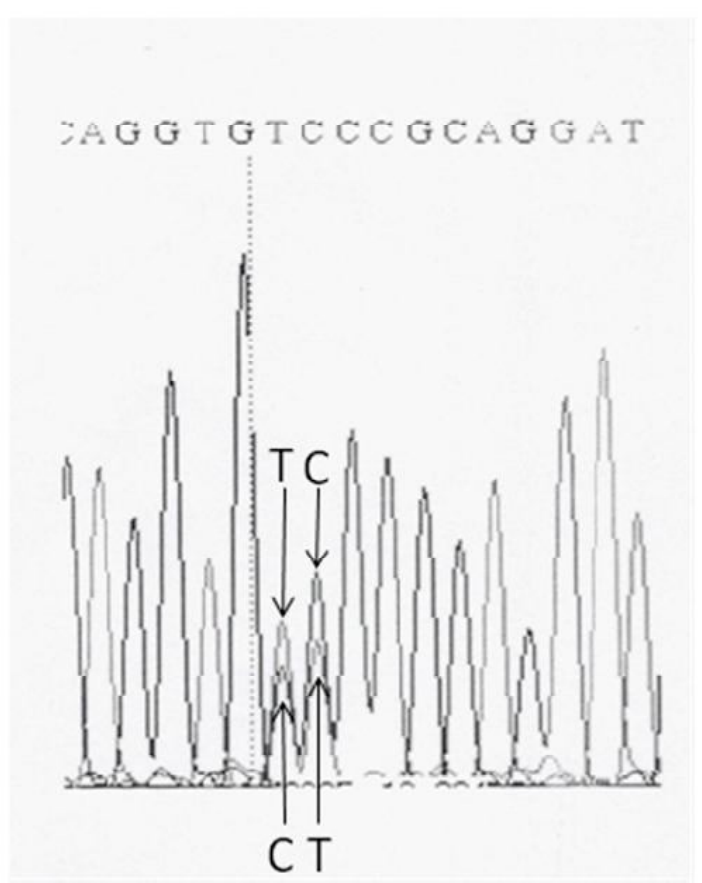

Figura 1 - (A) Alinhamento das sequências de aminoácidos da proteína ALS de $\boldsymbol{O}$. sativa (BAB20812) e de Sagittaria montevidensis, indicando os domínios C, A e D (sublinhado) e a mutação do amoniácido prolina (P) para phenilalanina (F) na posição 197 (Pro ${ }_{197}$ Phe), no domínio A. (B) Cromatograma de parte do domínio A do gene ALS de Sagittaria montevidensis, indicando a ocorrência dos nucleotídeos C e T de forma heterozigota nas posições 265 e 266. 
com o gene ALS de arroz, possuindo apenas três mutações de ponto. Duas dessas mutações estão localizadas fora dos domínios conservados do gene ALS, onde a ocorrência de mutações possui como consequência a resistência de plantas a herbicidas (MEROTTO et al., 2009). No entanto, uma mutação ocorreu no domínio A do gene ALS, correspondendo à posição 197 originalmente codificada para o aminoácido prolina e que, na sequência de sagitária, encontrou-se $o$ aminoacido phenilalanina (Figura 1A). Essa alteração caracteriza a ocorrência da mutação Pro $_{197}$ Phe no gene ALS de sagitária. A análise da sequência nucleotídica indicou que essa alteração resultou da mutação dos nucleotídeos CCC que codificam para o aminoácido prolina em espécies suscetíveis aos herbicidas inibidores da ALS para os nucleotídeos TCC que resultam no aminoácido phenilalanina. Observou-se que o gene ALS, na planta amostrada, encontrava-se em heterozigose (Figura 1B).

Atualmente são conhecidas sete mutações do gene ALS relacionadas com a resistência a herbicidas (MEROTTO et al., 2009; POWLES \& YU, 2010). As consequências dessas mutações são a diminuição de sensibilidade à inibição dos herbicidas que atuam nessa enzima. Entre as mutações do gene ALS, a mutação Pro $_{197}$ para os aminoácidos alanina, histidina, serina e triptofano, principalmente, é a que apresenta maior frequência entre os casos de plantas daninhas resistentes. No entanto, a mutação de prolina para phenilalanina não é reportada na literatura (TRANEL et al., 2010). Assim sendo, esses resultados sugerem a ocorrência de insensibilidade do local de ação como mecanismo de resistência a herbicidas inibidores de ALS em sagitária. Estudos adicionais de determinação dos níveis de resistência e do padrão de resistência cruzada e múltipla estão em desenvolvimento. Os resultados deste trabalho podem ser utilizados para o monitoramento do mecanismo de resistência em estudos de dinâmica de populações de forma a identificar a distribuição e a importância da resistência a herbicidas em sagitária. A prevenção do início da evolução da resistência a herbicidas inibidores da ALS em sagitária e o controle de indivíduos resistentes devem ser fundamentados na rotação de herbicidas com diferentes mecanismos de ação.

\section{REFERÊNCIAS}

CARVALHO, M.C.C.G.; SILVA, D.C.G. Sequenciamento de DNA de nova geração e suas aplicações na genômica de plantas.
Ciência Rural, v.40, p.735-744, 2010. Disponível em: <http:/ /www.scielo.br/scielo.php?script=sci_arttext\&pid=S0103$84782010000300040 \& \operatorname{lng}=\mathrm{pt} \& \mathrm{nrm}=\mathrm{i}$ so $\& \operatorname{tng} \mathrm{g}=\mathrm{pt}>$. Acesso em: 22 ago. 2010. doi: 10.1590/S0103-84782010000300040.

CONCENÇO, G. et al. Aspectos da resistência de Sagittaria montevidensis ao herbicida pirazosulfuron-ethyl inibidor da ALS. Planta Daninha. v.25, p.187-194, 2007. Disponível em: <http:/ /www.scielo.br/scielo.php?script=sci_arttext\&pid $=\mathrm{S} 0100$ $83582007000100021 \& \operatorname{lng}=\mathrm{en} \& \mathrm{nrm}=\mathrm{iso} \& \operatorname{lng}=\mathrm{pt}>$. Acesso em: 22 ago. 2010 . doi: 10.1590/S0100-83582007000100021.

CORBETT, C.A.L.; TARDIF, F.J. Detection of resistance to acetolactate synthase inhibitors in weeds with emphasis on DNA-based techniques: a review. Pest Management Science, v.62, p.584-597, 2006. Disponível em: <http:// onlinelibrary.wiley.com/doi/10.1002/ps.1219/full>. Acesso em: 22 ago. 2010 . doi: 10.1002/ps. 1219 .

GIBSON, K.D. et al. California arrowhead is a weak competitor in water-seeded rice. Weed Science, v. 49, p.381-384, 2001. Disponível em: <http://www.bioone.org/doi/full/10.1614/00431745\%282001\%29049\%5B0381\%3ACAIAWC\%5D2.0.CO\%3B2>. Acesso em: 22 ago. 2010. doi: 10.1614/00431745(2001)049[0381:CAIAWC]2.0.CO;2.

HEAP, I. The International Survey of Herbicide Resistant Weeds. Acesso em: 14 abr. 2010. Online. Disponível em: $<$ http://www.weedscience.com>.

MEROTTO JR., A.et al. Cross-resistance to herbicides of five ALS-inhibiting groups and sequencing of the ALS gene in Cyperus difformis L. Journal of Agricultural and Food Chemistry, v.57, p.1389-1398, 2009. Disponível em: <http:/ /pubs.acs.org/doi/abs/10.1021/jf802758c $>$. Acesso em: 22 ago. 2010. doi: $10.1021 / \mathrm{jf} 802758 \mathrm{c}$.

NOLDIN, J.A. et al. Resistência de Sagittaria montevidensis a herbicidas: primeiras evidências. In: CONGRESSO BRASILEIRO DE ARROZ IRRIGADO; REUNIÃO DA CULTURA DO ARROZ IRRIGADO, 23., 1999, Pelotas, RS. Anais... Pelotas: EmbrapaCPACT, 1999. p.566-569.

POWLES, S.P.; YU, Q. Evolution in action: plants resistant to herbicides. Annual Review of Plant Biology, v.61, p.317347, 2010. Disponível em: <http://arjournals.annualreviews.org/ doi/abs/10.1146/annurev-arplant-042809-112119>. Acesso em: 22 ago. 2010. doi:10.1146/annurev-arplant-042809112119 .

PAPPAS-FADER, T. et al. Resistance monitoring program for aquatic weeds to sulfonylurea herbicides in California rice fields. Rice Technical Working Group, v.25, p.165, 1994.

TRANEL, P.J. et al. ALS mutations from herbicideresistant weeds. Acesso em: 14 abr. 2010. Online. Disponível em: http://www.weedscience.org/mutations/MutDisplay.aspx $>$. 